\title{
Obesidade na infância e adolescência: associação da inflamação e resistência à insulina com alterações metabólicas
}

\author{
Rafaelle B. C. Chissini, ${ }^{1}$ Cecilia L. Oliveira, ${ }^{2 *}$ Denise T. Giannini, ${ }^{3}$ Maria Cristina C. Kuschnir ${ }^{4}$
}

\begin{abstract}
Resumo
A obesidade tem apresentado rápido aumento em sua prevalência em crianças e adolescentes. É um fato preocupante, uma vez que o excesso de gordura corporal está associado às alterações metabólicas consideradas fatores de risco cardiovascular. O possível elo entre as alterações metabólicas associadas à obesidade, principalmente a visceral, e um estado inflamatório subclínico pode ser a resistência à insulina. No entanto, a relação entre a resistência à insulina e o processo inflamatório é bidirecional, sendo assim, a inflamação leva ao prejuízo da sinalização da insulina em tecidos-alvo, que, por sua vez, piora o quadro inflamatório. Na infância e adolescência, já se constatam alterações metabólicas caracterizadas por um perfil lipídico alterado (aumento dos triglicerídeos e redução da HDL-c, bem como aumento das partículas da LDL-c, porém com tamanho menor e mais densas) e da pressão arterial associados a um estado inflamatório e resistência à insulina. Esse artigo tem como objetivo revisar a associação entre a resistência à insulina e inflamação e as alterações metabólicas em crianças e adolescentes obesos.
\end{abstract}

Descritores: Obesidade; Resistência à insulina; Inflamação; Criança; Adolescente.

\section{Abstract \\ Obesity in childhood and adolescence: association of inflammation and insulin resistance with me- tabolic changes}

Obesity has shown rapid increase in its prevalence in children and adolescents. It is a worrying fact, since excess of body fat is associated with metabolic changes, considered a cardiovascular risk factor. The possible link between the metabolic abnormalities, associated with obesity (especially visceral) and pro-inflammatory state, may be the insulin resistance. However, the relation between insulin resistance and the inflammatory process is bidirectional so the inflammation leads to an impairment of insulin signaling in target tissues, which also worsens inflammation. Metabolic disorders can be evidenced since childhood and adolescence and it is characterized by an altered lipid profile (increased triglycerides, decreased HDL-C and increases in particles of LDL-c, but this smaller and denser) and increased blood pressure associated with an inflammatory state and insulin resistance. This article aims to review the association between insulin resistance and inflammation with metabolic changes in obese children and adolescents.

Keywords: Obesity; Insulin resistance; Inflammation; Child; Adolescent.

\begin{abstract}
1. Instituto Nacional do Câncer. Rio de Janeiro, RJ, Brasil
2. Departamento de Nutrição Aplicada. Instituto de Nutrição. Universidade Estadual do Rio de Janeiro, Rio de Janeiro, RJ, Brasil.

3. Divisão de Nutrição. Hospital Universitário Pedro Ernesto. Universidade Estadual do Rio de Janeiro, Rio de Janeiro, RJ, Brasil.

4. Núcleo de Estudos da Saúde do Adolescente. Hospital Universitário Pedro Ernesto. Universidade Estadual do Rio de Janeiro, Rio de Janeiro, RJ, Brasil.
\end{abstract}

"Endereço para correspondência:

São Francisco Xavier, 524, 12 ㅇadar

Rio de janeiro, RJ, Brasil. CEP: 20559-900.

E-mail: cecilacroix@yahoo.com.br

Revista HUPE, Rio de Janeiro, 2015;14(3):41-49

doi: 10.12957/rhupe.2015.19895

Recebido em 19/03/2015. Aprovado em 16/07/2015.

\section{Resumen}

La obesidad en la infancia y adolescencia: asociación de la inflamación y la resistencia a la insulina con cambios metabólicos

Se ha mostrado un rápido incremento en la prevalencia de obesidad en niños y adolescentes. Es un hecho preocupante, ya que el exceso de grasa corporal está asociado con cambios metabólicos considerados factores de riesgo cardiovascular.La posible relación entre las alteraciones metabólicas asociadas a la obesidad, especialmente la visceral y estado inflamatorio subclínico, puede ser la resistencia a la insulina. Sin embargo, la relación entre la resistencia a la insulina y el proceso inflamatorio es bidireccional, por lo que la inflamación conduce al deterioro de la señalización de la insulina en tejidos diana, que a su vez empeora el cuadro inflamatorio. En la infancia y adolescencia, ya se evidencian alteraciones metabólicas, caracterizadas por un perfil lipídico alterado (incremento de triglicéridos y disminución de HDL-C, así como aumento de las partículas de LDL-c, pero más pequeñas y densas) y aumento de la presión arterial, asociados con un estado inflamatorio y resistencia a la insulina. Este artículo tiene como objetivo revisar la asociación entre la resistencia a la insulina e inflamación y las alteraciones metabólicas en niños y adolescentes obesos.

Palabras clave: Obesidad; Resistencia a la insulina; Inflamación; Niños; Adolescente. 


\section{Artigo de revisão}

\section{Introdução}

A obesidade, definida como o acúmulo de tecido adiposo localizado ou generalizado, é desencadeada por um desequilíbrio entre a quantidade de energia ingerida e dispendida associado ou não a distúrbios genéticos ou endócrinos. A etiologia da obesidade é complexa e multifatorial. Engloba fatores genéticos, metabólicos, ambientais, comportamentais e emocionais. A herança genética predispõe o desenvolvimento da obesidade. $\mathrm{O}$ risco para o distúrbio aumenta quando pelo menos um dos pais é obeso:é de 9\% na ausência de pais obesos, passa para 50\% quando um dos genitores é obeso e atinge $80 \%$ quando ambos têm obesidade. ${ }^{1}$

Oestudo Global Burden of Disease Report mostrou que a prevalência do excesso de peso em crianças eadolescentes vem aumentando substancialmente. Em países desenvolvidos, $23,8 \%$ dos meninos e $22,6 \%$ das meninas tinham excesso de peso em 2013. Nos países em desenvolvimento, as taxas passaram de $8,1 \%$ para $12,9 \%$ no sexo masculino e de $8,4 \%$ para $13,4 \%$ o feminino entre 1980 e $2013 .{ }^{2}$

No Brasil, a Pesquisa de Orçamentos Familiares (POF) 2008-2009, realizada pelo Instituto Brasileiro de Geografia e Estatística (IBGE) em parceria com o Ministério da Saúde, revelou um aumento contínuo no número de crianças e adolescentes com excesso de peso ao longo de 34 anos. Os resultados da última POF foram comparados com os dados do Estudo Nacional da Despesa Familiar (ENDEF), 1974-75 e a Pesquisa Nacional sobre Saúde e Nutrição (PNSN), 1989³. A prevalência de excesso de peso em meninos (5 a 9 anos) em 1974-1975 era de 10,9\% e aumentou para 15,0\% em 1989 e alcançou 34,8\% em 2008-2009.Padrão semelhante de aumento do excesso de peso é observado em meninas: 8,6\%, 11,9\% e 32,0\%, respectivamente. A evolução da prevalência de obesidade nos dois sexos repete, com frequências menores, a tendência descrita para o excesso de peso. Em adolescentes, o sobrepeso era de 3,7\% em meninos e 7,6\% em meninas, em1974/75, e aumentou para $21,7 \%$ e 19,4\%, respectivamente, em 2008/09.3

Oaumento da prevalência de excesso de peso concomitante às doenças crônicas não transmissíveis estimulou investigações que elucidassem uma fisiopatologia comum para tais comorbidades. O possível elo entre as alterações metabólicas associadas à obesidade, principalmente a visceral, e um estado inflamatório subclínico pode ser a resistência à insulina. ${ }^{4}$ Esse artigo tem como objetivo revisar a associação entre a resistência à insulina e inflamação com as alterações metabólicas em crianças e adolescentes obesos.

\section{Tecido adiposo e inflamação}

O tecido adiposo contém grandes quantidades de macrófagos, que podem ter função pró ou anti-inflamatória. ${ }^{5}$ Os macrófagos da série M1 secretam citocinas pró-inflamatórias, como o fator de necrose tumoral $\alpha$ (TNFa) e a interleucina 6 (IL-6). Ao contrário da série M1, os macrófagos da série M2 secretam moléculas anti-inflamatórias. Em condições homeostáticas normais, o fenótipo predominante é o M2. ${ }^{6}$ Entretanto, a obesidade leva a mudanças na composição de macrófagos do tecido adiposo, com predomínio da série M1, através de duas vias: conversão de macrófagos M2 em M1 e recrutamento de macrófagos M1 para dentro do tecido. ${ }^{6}$

A conversão dos macrófagos M2 a M1 pode ser induzida por múltiplos estímulos, como a lipotoxidade e a disfunção dos adipócitos, causadas pela hipertrofia, hipóxia e necrose celular. Os adipócitos necrosados estimulam o recrutamento e acúmulo de macrófagos M1.

Sbarbati e colaboradores realizaram uma pesquisa histológica do tecido adiposo de 19 crianças brancas, pré-púberes, com média de idade de 11 anos e observaram lesões elementares nos adipócitos do grupo dos obesos, mas não naqueles eutróficos. ${ }^{8}$ Em todos os obesos, foi demonstrado um envolvimento inflamatório por análise microscópica do tecido adiposo e a extensão das lesões foi dependente do IMC. Macrófagos e, com menor frequência, linfócitos e granulócitos foram encontrados na posição perivascular.

A distribuição do tecido adiposo branco se dá como tecido adiposo subcutâneo e como tecido adiposo visceral, representado pelos tecidos próximos ou infiltrados nas vísceras da cavidade abdominal. As diferenças entre o tecido adiposo subcutâneo e o visceral vão além da localização anatômica. No tecido adiposo visceral, o efeito lipolítico das catecolaminas (noradrenalina, adrenalina e dopamina) é mais pronunciado do que o efeito antilipolítico da insulina, acarretando maior liberação de ácidos graxos livres do que pelo tecido adiposo subcutâneo. Soma-se a essa característica o fato da IL-6 ser mais secretada pelos adipócitos viscerais do que pelos subcutâneos. ${ }^{9}$

Em nível sistêmico, a IL-6 e o TNF- $\alpha$ estimulam a produção de proteínas de fase aguda pelo fígado. Dentre elas, a proteína C reativa (PCR)é considerada a principal. A PCR é uma proteína de fase aguda produzida principalmente pelos hepatócitos, mas o tecido adiposo e o arterial também podem sintetizá-la. Eleva-se rapidamente em resposta ao trauma, inflamação e infecção. ${ }^{10}$

Contudo, nos últimos anos, pequenos aumentos 
na produção dessa proteína vêm sendo associados ao risco para as doenças cardiovasculares. ${ }^{11}$ Com o desenvolvimento de métodos de aferição altamente sensíveis, ficou possível detectar aumentos discretos da PCR, denominada PCR-us, indicando um estado inflamatório de baixa intensidade, presente no processo da aterosclerose. ${ }^{12} \mathrm{O}$ papel da PCR nesse processo relaciona-se à sua atuação sobre a homeostase vascular. Dentre suas ações, destacam-se: redução da disponibilidade do óxido nítrico; estímulo à liberação de IL-6 e TNF- $\alpha$, à expressão de moléculas de adesão e a apoptose das células endoteliais; aumento da captação de lipoproteína de baixa densidade (LDL-c) e da proliferação e migração das células musculares lisas. ${ }^{13}$

Em 51 crianças, Guran e colaboradores determinaram o ponto de corte para PCR que se correlacionava com a presença de fatores de risco cardiovascular: colesterol total (CT) aumentado, hipertensão arterial sistêmica (HAS), obesidade, lipoproteína de alta densidade (HDL-c) reduzida e história familiar de doença cardiovascular. Foi estabelecido um valor de PCR $>1,04 \mathrm{mg} / \mathrm{L}$ com $58 \%$ de sensibilidade e $92 \%$ de especificidade. ${ }^{14}$

Sabendo-se que elevações nos níveis de PCR sofrem influência interindividual e que a proteína pode estar associada a eventos cardiovasculares futuros, a dosagem da PCR-us é uma alternativa para detectar os obesos em maior risco. No entanto, na infância e adolescência são necessários mais estudos longitudinais que estabeleçam pontos de corte para essa faixa etária.

\section{Obesidade e resistência à insulina}

É bem estabelecida a associação entre obesidade e resistência à insulina. Entretanto, nem todos os obesos são resistentes à insulina e a resistência ao hormônio pode ocorrer em crianças e adultos sem excesso de peso. Vale relatar que a resistência à insulina é fisiológica em algumas fases da vida, como na gestação ou puberdade. ${ }^{15}$

A relação da resistência à insulina com excesso de peso pode ser intermediada por fatores inflamatórios. O TNF- $\alpha$ e a IL-6 são substâncias que têm papel pró inflamatório e desempenham importante influência no metabolismo dos carboidratos e lipídios. O TNF- $\alpha$ e a IL-6 prejudicam a sinalização da insulina, uma vez que são capazes de reduzir a fosforilação dos IRS e a sinalização da PI3K, com redução da síntese e translocação do GLUT-4 para a membrana celular.Já a interferência no metabolismo lipídico é provocada pela inibição da lipogênese, através da redução da expressão da lipase lipoprotéica. Em contrapartida, as citocinas inflamatórias estimulam a lipólise, aumentando a liberação de ácidos graxos livres para a circulação..$^{16} \mathrm{O}$ excesso de ácidos graxos em tecidos, como músculos e fígado, leva ao aumento intracelular de seus metabólitos, que ativam a proteína quinase $\mathrm{C}$ (PKC), inibindo a fosforilação dos IRS e levando a resistência à insulina. ${ }^{17}$

Outro fato a ser descrito é que a insulina exerce efeitos na síntese de proteínas hepáticas. O hormônio estimula a síntese de albumina, em detrimento de proteínas de fase aguda positiva, como a PCR. Portanto, na presença de resistência à insulina, pode haver aumento da PCR pela diminuição dos efeitos anti-inflamatórios do hormônio. ${ }^{18}$

\section{Obesidade, inflamação, resistência à insulina e alterações metabólicas}

O aumento da prevalência das doenças crônicas não transmissíveis estimulou investigações que elucidassem uma fisiopatologia comum para tais comorbidades. O possível elo entre as alterações metabólicas associadas à obesidade, principalmente a visceral e um estado inflamatório subclínico pode ser a resistência à insulina. ${ }^{4}$ A relação entre a resistência à insulina e o processo inflamatório é bidirecional, sendo assim, a inflamação leva ao prejuízo da sinalização da insulina em tecidos-alvo, que por sua vez piora o quadro inflamatório. ${ }^{18}$

Como já explicado acima, tanto as adipocinas pró-inflamatórias quanto o excesso de ácidos graxos livres interferem na ação da insulina. Uma vez que os tecidos tornam-se insensíveis à ação desse hormônio anabólico, a produção hepática de glicose não é inibida e a absorção de glicose pelo músculo e tecido adiposo fica prejudicada, desenvolvendo-se a hiperglicemia. ${ }^{19}$ Como mecanismo compensatório, as células $\beta$-pancreáticas passam a produzir mais hormônio, levando a um estado de hiperinsulinemia. Em longo prazo, o pâncreas se torna incapaz de compensar a resistência à insulina, e com isso, surge a intolerância à glicose e posteriormente o diabetes melittus tipo $2 .^{18}$

A dislipidemia aterogênica é caracterizada pelo aumento dos triglicerídeos (TG) e redução da HDL-c ${ }^{20}$. A obesidade também pode levar ao aumento das partículas da LDL-c, porém com tamanho menor e mais densas. Essas características favorecem a glicosilação e oxidação da lipoproteína, e, portanto, são mais prejudiciais ao processo de aterogênese. ${ }^{20}$

No estado de resistência à insulina, o hormônio também não é capaz de inibir a lipólise dos TG estocados no tecido adiposo. Dessa forma, o fluxo de ácidos graxos livres para a circulação e o fígado aumenta. 


\section{Artigo de revisão}

Além disso, a insulina não consegue ativar de forma satisfatória a lipase lipoprotéica, encontrada na superfície endotelial dos vasos sanguíneos, com função de hidrolisar os TG transportados pelos quilomícrons e pela lipoproteína de muito baixa densidade (VLDL-c) na circulação, para liberação dos ácidos graxos livres para os tecidos. O aumento da secreção de VLDL-c pelo fígado, em reposta ao acúmulo de gordura no órgão; e a redução do clearance da VLDL-c e quilomícrons do sangue explicam a hipertrigliceridemia. ${ }^{20}$

A diminuição da HDL-c é resultado da menor disponibilidade de apolipoproteínas e fosfolipídios provenientes da quebra dos quilomícrons e VLDL-c, que são usados para a formação da HDL-c. Outro mecanismo proposto é que a atividade da proteína de transferência de ésteres de colesterol parece estar acentuada na obesidade, levando a maior transferência dos ésteres de colesterol da HDL-c para os quilomícrons e VLDL-c. ${ }^{20}$

Com relação à pressão arterial sistêmica, foi demonstrado que o risco para HAS em crianças e adolescentes com excesso de peso foi de 2,5 a 3,7 vezes maior do que naquelas com IMC dentro da normalidade. ${ }^{21}$ Existem alguns mecanismos que podem explicar esta alteração na obesidade. A hiperinsulinemia por si só já contribui para o aumento da pressão arterial. Nesse caso, o hormônio estimula o sistema nervoso simpático renal, resultando em vasoconstricção e diminuição do fluxo de sangue para os rins, com liberação de renina, que ativa o sistema renina-angiotensina-aldosterona. Consequentemente, sódio e água são retidos na circulação, o que ocasiona o aumento da pressão arterial. ${ }^{21}$ A leptina, hormônio produzido pelo tecido adiposo, também estimula o sistema nervoso simpático. ${ }^{22}$ Já a adiponectina tem correlação negativa com a pressão arterial em crianças e adolescentes obesos. ${ }^{23}$ Outro processo que, provavelmente, contribui para a alteração da pressão arterial é a inflamação. As adipocinas inflamatórias podem agir de duas formas: levar a disfunção endotelial, prejudicando a vasodilatação; ou ativar o sistema nervoso simpático. ${ }^{21}$

Estudos sobre as alterações metabólicas provocadas pelo excesso de peso em crianças e adolescentes podem ser observados na tabela 1.

Em 2000, foi descrito pela primeira vez a associação entre a obesidade e a inflamação em crianças. O estudo foi conduzido por Cook e colaboradores ${ }^{33}$, em 699 crianças entre 10-11 anos. Os seus resultados mostraram um nível de PCR 270\% maior naqueles com peso mais elevado. Pouco depois, o achado foi confirmado por uma pesquisa, que utilizou os dados da pesquisa norte- -americana de saúde e nutrição, o National Health and Nutrition Examination SurveyIII, com 3.512 jovens entre 8-16 anos, em que meninos e meninas com excesso de peso tiveram um nível de PCR 3,74 e 3,17 vezes maior, respectivamente, do que aqueles com peso dentro dos padrões de normalidade. ${ }^{34}$

No Brasil, foi conduzida uma pesquisa transversal comparativa de grupos paralelos, com 224 crianças e adolescentes entre 2 e 19 anos. Os valores de PCR elevaram-se à medida que o IMC aumentava, corroborando os resultados dos estudos internacionais anteriormente mencionados. ${ }^{35}$ Outros estudos também mostraram forte associação desta proteína com a circunferência da cintura e IMC, como pode ser observado na tabela 2.

A relação da PCR com distúrbios metabólicos causados pelo excesso de peso já foi investigada na infância e adolescência. Em alguns estudos, a PCR foi independentemente associada ao perfil lipídico. Encontrou-se correlação positiva com os níveis de TG e negativa com o HDL-c. ${ }^{36,37}$ Numa outra pesquisa com 115 crianças e adolescentes obesos, entre 6 e 18 anos, 24\% da amostra apresentava síndrome metabólica, ${ }^{38}$ definida como um conjunto de comorbidades (circunferência da cintura aumentada; TG, glicemia e pressão arterial elevados; e HDL-c diminuído), que aumentam o risco para as doenças cardiovasculares e para o diabetes melittus tipo 2. Entre os que tinham a síndrome metabólica, o nível de PCR foi 1,9 vezes maior do que aqueles que não preenchiam os critérios para a síndrome. ${ }^{38}$ Resultados similares também foram encontrados em outros trabalhos brasileiros e internacionais, dispostos na Tabela 2 . Frequentemente, quanto maior o número de componentes da síndrome metabólica presentes, maiores são os valores de PCR encontrados.

\section{Conclusão}

As alterações metabólicas estão presentes em crianças e adolescentes obesos. Parece existir já uma associação entre resistência à insulina e a inflamação com as alterações metabólicas nesses indivíduos, sendo a relação da inflamação com a resistência à insulina bidirecional.

\section{Referências}

1. Sociedade Brasileira de Endocrinologia e Metabologia (SBEM); Sociedade Brasileira de Clínica Médica (SBCM). Obesidade: etiologia. Projeto Diretrizes [periódico na internet]. 2005 Set [acesso em 2014 Dez 09]; [Aproximadamente 7p.]. Disponível em: http://www.projetodiretrizes.org.br/4_volume/22-Obesidade-etiologia.pdf.

2. Marie NG, Tom FBS, Margaret RBA, et al. Global, regional, and 
Rafaelle B. C. Chissini e cols. • Obesidade na infância e adolescência: associação da inflamação e resistência à insulina com alterações metabólicas

Tabela 1. Estudos que relacionam o excesso de peso com alterações metabólicas em crianças e adolescentes.

\begin{tabular}{c|l}
\hline \multicolumn{1}{|c|}{ Publicação } & \multicolumn{1}{c}{ População do estudo } \\
& $\begin{array}{l}\text { Estudo caso-controle com crianças entre } 6 \\
\text { a } 17 \text { anos, onde: casos }(n=21) \text { eram aque- } \\
\text { Akinci e colaboradores }{ }^{24}\end{array}$ \\
& les com risco para sobrepeso (IMC/I entre \\
p85-p94) e controles $(n=20)$ eram aqueles \\
eutróficos $(I M C / I$ entre $p 25-p 74)$.
\end{tabular}

Lambert e colaboradores ${ }^{25}$

Estudo com 1.778 meninos e 1.835 meninas de 13 e 16 anos. O sobrepeso foi definido como IMC $\geq$ p85 e a obesidade como IMC $\geq$ p95, de acordo com CDC, 2000.

Foi comparado um grupo formado por obesos - IMC/I > p97 ( $n=70$ ) com um grupo controle $(n=55)$ de eutróficos, com idade média de $12,9 \pm 3,3$

Estudo transversal com 704 adolescentes, entre 10 e 15 anos, de duas escolas públicas da cidade de Cubatão, SP.

Silva e colaboradores ${ }^{27}$

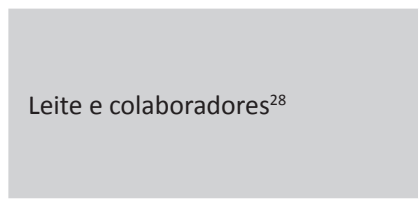

Estudo transversal com 71 meninas $(13,39 \pm$ 1,81 anos) e 56 meninos (13,10 $\pm 1,97$ anos) acompanhados na Unidade de Endocrinologia Pediátrica do Hospital de Clínicas em Curitiba.

Cobayashi e colaboradores $^{29}$

Estudo brasileiro, caso-controle, com adolescentes entre 14 e 19 anos: 163 com excesso de peso (IMC $\geq$ p85) e 151 eutróficos.

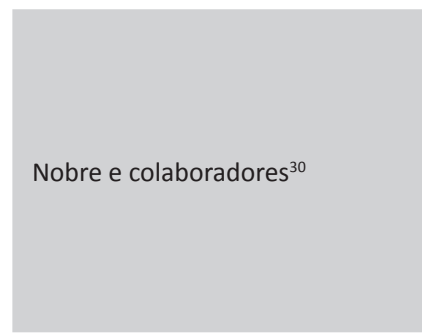

Maggio e colaboradores ${ }^{31}$

Estudo transversal com 67 obesos e 62 euDomingos e colaboradores ${ }^{32}$ tróficos (10,9 $\pm 2,8$ anos).

Estudo transversal com 154 adolescentes, en-

Estudo transversal com 571 adolescentes, entre 10 e 17 anos, da cidade de Barbacena, Minas Gerais. A classificação do estado nutricional foi de acordo com a OMS, 2007. tre 10 e 17 anos, da rede pública de Cambira, região norte do Paraná.

\section{Obesidade e alterações metabólicas}

O HOMA-IR foi maior no grupo com risco para sobrepeso - HOMA-IR $=1,67(0,28-5,0)$ do que no grupo controle-HOMA-IR = 1,01 $(0,20-3,12)$, com $p=0,031$. A circunferência de cintura teve a melhor correlação com o HOMA-IR $(r=0,509, p<0,001)$ do que o IMC e peso.

O sobrepeso e a obesidade foram encontrados em $14 \%$ e $10 \%$ dos meninos, e $14 \%$ e $7 \%$ das meninas, respectivamente. A insulina, TG e PAS foram significativamente maiores naqueles com sobrepeso e obesidade $(\mathrm{P}<$ $0,0001)$. Aproximadamente, $1 / 3$ dos obesos tiveram, no mínimo, duas variáveis alteradas (HDL-c, TG, insulina, glicemia, PAS).

Os obesos tiveram maior CT $(p<0,05)$, TG $(P<0,01)$, LDL-C oxidada $(p<0,001)$, glicemia $(p<0,001)$, insulina de jejum $(p<0,001)$, HOMA-IR $(p<0,001)$, PAS $(p<0,01)$, PAD ( $p$ $<0,01)$ do que os eutróficos; e menor HDL-c $(p<0.001)$ do que os eutróficos.

Do total da amostra, 535 não apresentavam excesso de peso e 169 tinham excesso de peso (IMC $\geq$ p85). Dos que não tinham excesso de peso, $17 \%$ tinha pressão arterial aumentada. Já no grupo com excesso de peso, a prevalência de pressão arterial elevada foi de $31,4 \%$, sendo $p=0,00008$.

Os meninos obesos apresentaram maiores proporções de HDL-c diminuído ( $p=0,004)$, LDL-c $(p=0,016)$ e TG $(p=0,04)$ aumentados em relação aos não obesos. Já as meninas obesas apresentaram HDL-c menor $(p=0,02)$ do que as não obesas.

Os adolescentes com excesso de peso apresentaram maiores frequências para todos os fatores de risco cardiovascular estudados (perfil lipídico, pressão arterial e insulina basal) do que os eutróficos. Porém só houve diferença estatística para HDL-c $(p=0,002)$, TG $(p=0,01)$, insulina $(p=0,000)$, PAS $(p=0,000)$ e PAD $(p=0,000)$.

O percentual de adolescentes com PAS $(p=0,00), \operatorname{PAD}(p$ $=0,01)$ e PAS/PAD $(p=0,00)$ elevadas foi mais alto entre aqueles com excesso de peso. Além disso, a chance de PAS elevada foi 2,7 vezes maior nos adolescentes com excesso de peso do que nos eutróficos. Em relação à circunferência de cintura, aqueles com circunferência de cintura aumentada ( $\geq p 75$ ) tiveram maior prevalência de $\operatorname{PAS}(p=0,00), \operatorname{PAD}(p=0,00)$ e PAS/PAD $(p=0,00)$ alteradas do que aqueles com circunferência de cintura normal.

O grupo dos obesos teve níveis de insulina significativamente maiores em relação aos eutróficos $(p<0,001)$.

A prevalência de pressão arterial aumentada foi maior entre os adolescentes com excesso de peso do que entre os eutróficos $(p=0,032)$ e também foi maior naqueles com circunferência de cintura aumentada $(p=0,003)$. Os indivíduos com circunferência de cintura aumentada apresentaram 3,23 vezes mais chance de apresentar pressão arterial elevada.

$\mathrm{CT}$ = colesterol total; HDL-c = lipoproteína de alta densidade; HOMA-IR = modelo homeostático de avaliação da resistência à insulina; $I M C$ = índice de massa corporal; IMC/I = índice de massa corporal por idade; LDL-C = lipoproteína de baixa densidade; OMS = Organização Mundial de Saúde; PAD = pressão arterial diastólica; PAS = pressão arterial sistólica; TG = triglicerídios. 


\section{Artigo de revisão}

Tabela 2. Estudos que avaliaram a associação da proteína C reativa ultrassensível com a obesidade e fatores de risco cardiovascular em crianças e adolescentes.

\begin{tabular}{|c|c|c|}
\hline Publicação & População do estudo & PCR e obesidade \\
\hline Visser e colaboradores 34 & $\begin{array}{l}\text { Estudo transversal. Utilizou o } \\
\text { banco do NHANES1988-1994. A } \\
\text { amostra total foi composta por } \\
3.512 \text { crianças entre } 8-16 \text { anos. }\end{array}$ & $\begin{array}{l}\text { A PCR esteve elevada (PCR } \geq 0,22 \mathrm{mg} / \mathrm{dL} \text { ) } \\
\text { em } 7,1 \% \text { dos meninos e } 6,1 \% \text { das meninas. } \\
\text { As crianças com sobrepeso (IMC/I }>\text { p } 85 \text { ) } \\
\text { tiveram maior PCR do que as crianças com } \\
\text { peso normal. Após ajuste para fatores de } \\
\text { confundimento, foi encontrado: meninos } \\
\text { com sobrepeso (OR = } 3,74[1,66-8,43]) \text {, } \\
\text { meninas com sobrepeso (OR = 3,17 [1,60- } \\
6,28] \text { ), baseado no IMC. }\end{array}$ \\
\hline Ford $^{39}$ & $\begin{array}{l}\text { Foi usado o banco do NHANES } \\
1999-2000(n=2846 \text {, idade }=3 \\
\text { a } 17 \text { anos). }\end{array}$ & $\begin{array}{l}\text { O IMC foi o melhor preditor para a PCR } \\
\text { de acordo com análise de regressão linear } \\
\text { múltipla (meninos: } 3-7 \text { anos } p=0,036 ; 8-17 \\
\text { anos } p<0.001 ; \text { meninas: } 3-7 \text { anos } p<0,004 \text {; } \\
\text { 8-17 anos } p<0.001 \text { ). }\end{array}$ \\
\hline Lambert e colaboradores ${ }^{36}$ & $\begin{array}{l}\text { Estudo canadense ( } n=2224 \text { cri- } \\
\text { anças/adolescentes, com idade } \\
\text { de } 9,13 \text { e } 16 \text { anos). }\end{array}$ & $\begin{array}{l}\text { Valores de PCR > 3,0 mg/L foram encon- } \\
\text { trados em } 7,7 \%, 5,5 \% \text { e } 12,8 \% \text { das crianças } \\
\text { com } 9,13 \text { e } 16 \text { anos, respectivamente. } \\
\text { Foi encontrada forte relação entre PCR e } \\
\text { IMC e insulina. Após ajuste para IMC, a } \\
\text { associação entre PCR e insulina foi atenu- } \\
\text { ada, porém a associação entre IMC e PCR } \\
\text { não mudou após ajuste para insulina. A } \\
\text { cada aumento de } 1 \text { SD para o IMC, a PCR } \\
\text { aumentou em } 52 \% \text {. }\end{array}$ \\
\hline
\end{tabular}

Foi usado o banco do NHANES 1999-2000 ( $\mathrm{n}=1366$, idade $=12$ a 17 anos). Para diagnóstico da Síndrome Metabólica usaram o NCEP-ATP-III.

\section{PCR e fatores de risco cardiovascular} A PCR teve associação significativa em amIMC (meninos: $r=0,39, p \leq 0,05$; meninas $r=0,41, p \leq 0,05$ ) e PAS (meninos/meninas: $r=0,20, p \leq 0,05)$.

Após ajuste para idade, sexo, etnia, tabagismo e possíveis doenças inflamatórias, as crianças com PCR no maior percentil (p95) tiveram PAS e TG aumentados em 1,4, 1,7, respectivamente, e HDL-c diminuída em 2,3 vezes a mais do que aqueles com PCR abaixo do $\mathrm{p} 75$.

A média para a PCR foi maior naqueles com Síndrome Metabólica (PCR $=3,8 \mathrm{mg} / \mathrm{L}$ ) do que naqueles sem Síndrome Metabólica SM. $(P C R=1,4 \mathrm{mg} / \mathrm{L}) \cdot 38,4 \%$ daqueles com Síndrome Metabólica tiveram PCR > $3 \mathrm{mg} / \mathrm{L}$, enquanto naqueles sem a Síndrome Metabólica, esse valor foi encontrado em $10,3 \%$ ( $p=0,007)$. Dentre os componentes da Síndrome Metabólica, apenas a circunferência de cintura foi independentemente associada à PCR.

$15,8 \%$ da amostra teve PCR entre 3-10 mg/ dL. Níveis aumentados de PCR foram associados ao pior perfil cardiovascular, ou seja, maior adiposidade, resistência à insulina e perfil lipídico. Após análise multivariada, a circunferência de cintura foi fator independente para o aumento da PCR.

A PCR teve correlação positiva com IMC, TG, insulina e HOMA-IR e negativa com HDL-c. O IMC, TG, insulina e HOMA-IR foram significativamente maiores naqueles com maior PCR $(p<0,05)$.

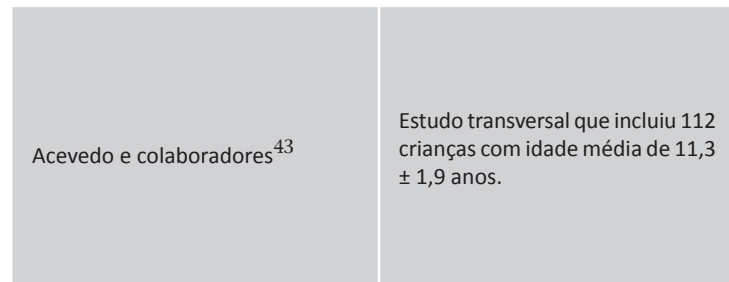

Estudo brasileiro transversal com parativo de grupos paralelos, sendo um grupo de crianças e adolescentes com excesso de peso $(n=131)$ e grupo controle com crianças e adolescentes sem excesso de peso $(n=114)$. A idade variou entre 2,3 a 19 anos.
Entre os meninos, foi encontrada correlação significativa entre a PCR e IMC ( $r=$ $0,29, p<0,001)$, circunferência de cintura ( $r=0,41, p<0,01)$ e LDL-c $(r=0,28, p<0,01)$. Nas meninas, só foi encontrada correlação significativa com o IMC $(r=0,43, p<0,001)$. No grupo total, o melhor preditor para a PCR-us elevada foi o IMC (OR $=2,04$ $[1,30-3,21])$.

O grupo com excesso de peso apresentou maiores concentrações de PCR-us ( $p<$ $0,0005)$. Os valores de PCR-us correlacionaram-se com o IMC $(p<0,0001)$ e TG $(p=0,05)$. Porém, após ajuste para IMC, a relação com os TG e PCR deixou de ter significância. 
Rafaelle B. C. Chissini e cols. • Obesidade na infância e adolescência: associação da inflamação e resistência à insulina com alterações metabólicas

Tabela 2 (continuação). Estudos que avaliaram a associação da proteína C reativa ultrassensível com a obesidade e fatores de risco cardiovascular em crianças e adolescentes.

\begin{tabular}{|c|c|c|}
\hline $\begin{array}{l}\text { Cardoso-Saldaña e colabora- } \\
\text { dores }^{37}\end{array}$ & $\begin{array}{l}\text { Estudo transversal com } 325 \text { ad- } \\
\text { olescentes mexicanos entre } 12 \text { e } \\
16 \text { anos. Investigaram a relação da } \\
\text { PCR-us com os componentes da } \\
\text { Síndrome Metabólica e resistência } \\
\text { à insulina. Para a classificação da } \\
\text { Síndrome Metabólica usaram o } \\
\text { NCEP-ATP-III. }\end{array}$ & $\begin{array}{l}\text { A Síndrome Metabólica foi diagnosticada } \\
\text { em } 13 \% \text { da amostra total. Dentre os com- } \\
\text { ponentes da Síndrome Metabólica, os mais } \\
\text { frequentes foram: HDL-c ( } 50 \%) \text {, TG elevados } \\
(35 \%) \text { e circunferência da cintura elevada } \\
(28 \%) \text {. Os maiores valores para PCR foram } \\
\text { encontrados naqueles com a Síndrome Me- } \\
\text { tabólica ( } p<0,007) \text {. A PCR foi positivamente } \\
\text { relacionada à circunferência de cintura, TG } \\
\text { ( } p<0,01) \text { e insulina ( } p<0,001 \text { ) e negati- } \\
\text { vamente com HDL-c }(p<0,01) \text {. Na análise } \\
\text { de regressão múltipla, o IMC e HOMA-IR } \\
\text { contribuíram em } 10,4 \% \text { e } 12,7 \% \text { para os } \\
\text { níveis de PCR, respectivamente. }\end{array}$ \\
\hline
\end{tabular}

Estudo caso-controle com crianças entre 6 a 17 anos, onde: casos $(n=21)$ eram aqueles com risco para sobrepeso (IMC/I entre p85-p94) e controles $(n=20)$ eram aqueles eutróficos (IMC/I entre p25-p74).

Akinci e colaboradores ${ }^{24}$

\begin{tabular}{|c|c|}
\hline Lande e colaboradores ${ }^{44}$ & $\begin{array}{l}\text { Foi usado o banco do NHANES } \\
\text { 1999-2004 ( } n=6112 \text {, idade = } 8 \text { a } 17 \\
\text { anos. Foi aplicada análise bivaria- } \\
\text { da para comparar valores de PCR } \\
>3 \mathrm{mg} / \mathrm{L} \text { e } \leq 3 \mathrm{mg} / \mathrm{L} \text { com a pressão } \\
\text { arterial e outros fatores de risco } \\
\text { cardiovascular e regressão linear } \\
\text { multivariada para avaliar a relação } \\
\text { entre a pressão arterial e PCR). }\end{array}$ \\
\hline
\end{tabular}

Foi comparado um grupo formado por obesos $-\mathrm{IMC} / \mathrm{I}>\mathrm{p} 97(\mathrm{n}=70)$ Mangge e colaboradores ${ }^{26}$ com um grupo controle $(n=55)$ de eutróficos, com idade média de $12,9 \pm 3,3$.

\begin{tabular}{|l|l|}
\hline Estudo brasileiro com 407 crianças \\
Oliveira e colaboradores ${ }^{45}$ & $\begin{array}{l}\text { idade de } 11,3 \pm 3,2 \text { anos. Foram } \\
\text { divididos em } 2 \text { grupos: com Sín- } \\
\text { drome Metabólica }(n=72) \text { e sem } \\
\text { Síndrome Metabólica }(n=335) .\end{array}$ \\
\hline
\end{tabular}

Estudo transversal com crianças e Soriano-Guillén e colaboradores 38 adolescentes obesas ( $\mathrm{z}$-score $>+2)$ entre 6-18 anos $(n=115)$.

\begin{tabular}{|c|c|c|}
\hline & & \\
\hline Barja e colaboradores ${ }^{46}$ & $\begin{array}{l}\text { Estudo transversal ( } n=209 \text { cri- } \\
\text { anças, idade média }=11,5 \pm 2 \text { ). }\end{array}$ & $\begin{array}{l}\text { Quanto mais fatores de risco cardiovascular } \\
\text { associados, maiores os valores de PCR (sem } \\
\text { fator de risco }-\mathrm{PCR}=0,69 \pm 0,9 ; 1 \text { fator de } \\
\text { risco }-\mathrm{PCR}=1,75 \pm 3 ; 2 \text { fatores de risco }- \\
\mathrm{PCR}=1,75 \pm 2 ; 3 \text { fatores de risco }-\mathrm{PCR}= \\
1,82 \pm 2 \text { com } \mathrm{p}<0,01 \text { ). }\end{array}$ \\
\hline
\end{tabular}

A PCR foi maior no grupo com risco para sobrepeso - PCR $=0,90 \mathrm{mg} / \mathrm{L}(0,10-3,20)$ do que no grupo controle $-\mathrm{PCR}=0,47 \mathrm{mg} / \mathrm{L}$ $(0,10-1,60)$, com $p=0,026$.

Os obesos tiveram maior PCR $(p<0.001)$ do que os

A média para PCR foi maior no grupo com Síndrome Metabólica $(p<0,001)$. A PCR teve associação significativa $(p<0,001)$ com a resistência à insulina, Síndrome Metabólica, circunferência de cintura, IMC, HAS, TG e HDL-c. Porém, após ajuste para IMC, as associações foram eliminadas. No entanto, o ajuste para HOMA-IR não elimiSíndrome Metabólica e a PCR. $O$ excesso de peso (OR=7,9 $[4,7-13,4])$, HAS (OR=2,3 [1,3$4,2]$ ) e TG elevados ( $O R=2,3[1,5-3,7])$ foram independentemente associados com a PCR.

24\% apresentavam Síndrome Metabólica. Aqueles com a Síndrome Metabólica tiveram maior $\mathrm{PCR}=3,8 \mathrm{mg} / \mathrm{L}(2,8-4,8)$ do que aqueles sem a Síndrome Metabólica $-P C R=2,0 \mathrm{mg} / \mathrm{L}(1,5-2,5)$, com $\mathrm{p}<0,01$. Após análise multivariada, as variáveis que mais influenciaram a PCR foram o IMC, TG

Quanto mais fatores de risco cardiovascula associados, maiores os valores de PCR (sem $1,82 \pm 2 \operatorname{com} p<0,01)$ nou a associação entre os componentes da 


\section{Artigo de revisão}

Tabela 2 (continuação). Estudos que avaliaram a associação da proteína C reativa ultrassensível com a obesidade e fatores de risco cardiovascular em crianças e adolescentes.

\begin{tabular}{|c|c|c|}
\hline DeBoer e colaboradores[47] ${ }^{2147}$ & $\begin{array}{l}\text { Estudo com dados do NHANES } \\
\text { 1999-2008. Foram analisados os } \\
\text { dados dos adolescentes ( } n=3.559 \text { ) } \\
\text { entre } 12-19 \text { anos, composto por } \\
\text { negros não hispânicos, brancos } \\
\text { não hispânicos e hispânicos. O } \\
\text { objetivo do estudo foi avaliar se } \\
\text { havia variação para o aumento } \\
\text { da PCR entre as diferentes etnias } \\
\text { nos adolescentes com Síndrome } \\
\text { Metabólica (NCEP-ATP-III). }\end{array}$ & $\begin{array}{l}\text { Para todas as etnias, em ambos os sexos, } \\
\text { os adolescentes com Síndrome Metabólica } \\
\text { tiveram maior PCR }(p<0,01) \text {. Com exceção } \\
\text { da PAD e glicemia de jejum, todos os outros } \\
\text { componentes da Síndrome Metabólica } \\
\text { foram significativamente correlacionados } \\
\text { com a PCR em todas as etnias e em ambos } \\
\text { os sexos. }\end{array}$ \\
\hline
\end{tabular}

HAS = hipertensão arterial sistêmica; HDL-c = lipoproteína de alta densidade; HOMA-IR = modelo homeostático de avaliação da resistência à insulina; IMC = índice de massa corporal; IMC/I = índice de massa corporal por idade; LDL-c = lipoproteína de baixa densidade; NCEP-ATP III = National Cholesterol Education Program - Adult Treatment Panel III; NHANES = National Health and Nutrition Examination Survey; $P A D$ = pressão arterial diastólica; $P A S=$ pressão arterial sistólica; $P C R$ = proteína $C$ reativa; $P C R-u s=$ proteína $C$ reativa ultrassensível; TG = triglicerídios.

national prevalence of overweight and obesity in children and adults during 1980-2013: a systematic analysis for the Global Burden of Disease Study 2013. The Lancet. 2014;384:766-81.

3. Instituto Brasileiro de Geografia e Estatística (IBGE). Pesquisa de Orçamentos Familiares 2008-2009. Antropometria e estado nutricional de crianças, adolescentes e adultos no Brasil [base de dados da Internet]. Rio de Janeiro: IBGE. c2009 [acesso em 2014 Dez 09] Disponível em: http://www.ibge.gov.br/home/ estatistica/populacao/condicaodevida/pof/2008_2009_encaa/.

4. Volp ACP, Alfenas RCG, Costa NMB, et al. Capacidade dos biomarcadores inflamatórios em predizer a síndrome metabólica. Arq Bras Endrocrinol Metab. 2008; 52(3): 537-49.

5. Donath MY, Shoelson SE. Type 2 diabetes as an inflammatory disease. Nat Rev Immunol. 2011;11(2):98-107.

6. Osborn O, Olefsky JM. The cellular and signaling networks linking the immune system and metabolism in disease. Nat Med. 2012;18(3):363-74.

7. Lumeng CN, DelProposto JB, Westcott DJ, et al. Phenotypic switching of adipose tissue macrophages with obesity is generated by spatiotemporal differences in macrophage subtypes. Diabetes. 2008;57(12):3239-46.

8. Sbarbati A, Osculati F, Silvagni D, et al. Obesity and inflammation: evidence for an elementary lesion. Pediatrics. 2006;117(1):220-3.

9. Wajchenberg BL. Subcutaneous and visceral adipose tissue: their relation to the metabolic syndrome. Endocr Rev. 2000;21(6):697-738.

10. Rexrode KM, Pradhan A, Mansos JE, et al. Relationship of total and abdominal adiposity with CRP and IL-6 in women. Ann Epidemiol. 2003;13(10):674-82.

11. Santos MG, Pegoraro M, Sandrini F, et al. Fatores de risco no desenvolvimento da aterosclerose na infância e adolescência. Arq Bras Cardiol. 2008;90(4):301-8.

12. Ridker PM. Clinical application of $\mathrm{C}$-reactive protein for cardiovascular disease detection and prevention. Circulation. 2003 107:363-9.

13. Lemieux I, Pascot A, Prud'home D, et al. Elevated C-reactive protein: another component of the atherothrombotic profile of abdominal obesity. Arterioscler Thromb Vasc Biol. 2001;21:961-7.

14. Guran O, Akalin F, Ayabakan C, et al. High-sensitivity c-reactive protein in children at risk for coronary artery disease. Acta
Paediatr. 2007;96(8):1214-9.

15. Goran MI, Gower BA. Longitudinal study on pubertal insulin resistance. Diabetes. 2001;50:2444-50.

16. Hsueh WA, Law R. The central role of fat and effect of peroxisome proliferator-activated and cardiovascular disease. Am J Cardiol. 2003;92(4A):3-9.

17. Chavez JA, Summers SA. A ceramide-centric view of insulin resistance. Cell Metab. 2012;15(5):585-94.

18. Dandona P, Chaudhuri A, Ghanim H, et al. Proinflammatory effects of glucose and anti-inflammatory effects of insulin: relevance to cardiovascular disease. Am J Cardiol. 2007;99(4):15-26.

19. D'Adamo E, Caprio S. Type 2 diabetes in youth: epidemiology and pathophysiology. Diabetes Care. 2011;34 Suppl 2:S161-5.

20. Franssen R, Monajemi H, Stroes ESG, et al. Obesity and dyslipidemia. Med Clin N Am. 2011;95(5):893-902.

21. Becton LJ, Shatat IF, Flynn JT. Hypertension and obesity: epidemiology, mechanisms and clinical approach. Indian J Pediatr. 2012; 79(8):1056-61.

22. Grontved A, Steene-Johannessen J, Kynde I, et al. Association between plasma leptin and blood pressure in two population-based samples of children and adolescents. J Hypertens. 2011;29(6):1093-100.

23. Shatat IF, Freeman KD, Vuguin PM, et al. Relationship between adiponectin and ambulatory blood pressure in obese adolescents. Pediatr Res.2009;65:691-5

24. Akinci G, Akinci B, Coskun S, et al. Evaluation of markers of inflammation, insulin resistance and endothelial dysfunction in children at risk for overweight. Hormones. 2008;7(2):156-62.

25. Lambert M, Delvin EE, Levy E, et al. Prevalence of cardiometabolic risk factors by weight status in a population-based sample of Quebec children and adolescents. Can J Cardiol. 2008;24(7):575-83.

26. Mangge H, Almer G, Haj-Yahya S, et al. Preatherosclerosis and Adiponectin Subfractions in Obese Adolescents. Obesity. 2008;16(12):2578-84.

27. Silva MCP, Ramos CHB, Costa RF. Estado nutricional e níveis pressóricos de escolares adolescentes da cidade de Cubatão - SP, Brasil. Rev Bras Crescimento Desenvolvimento Hum. 2008;18(3):288-97.

28. Leite N, Cieslak F, Milano GE,et al. Associação entre o perfil lipídico e medidas antropométricas indicadoras de adiposidade em adolescentes. Rev Bras Cineantropom Desempenho Hum. 
Rafaelle B. C. Chissini e cols. • Obesidade na infância e adolescência: associação da inflamação e resistência à insulina com alterações metabólicas

2009;11(2):127-33

29. Cobayashi F, Oliveira FLC, Escrivão MAMS, et al. Obesidade e fatores de risco cardiovascular em adolescentes de escolas públicas. Arq Bras Cardiol. 2010; 95(2):200-6.

30. Nobre LN, Sammour SNF, Sobrinho PSC. Índice de massa corporal e circunferência de cintura como preditores de pressão arterial alterada em adolescentes. Rev Med Minas Gerais. 2011;21(4):404-12.

31. Maggio ABR, Wacker J, Montecucco F, et al. Serum resistin and inflammatory and endothelial activation markers in obese adolescents. J Pediatr. 2012;161(6):1022-7.

32. Domingos E, Domingues V, Júnior RP, et al. Associação entre estado nutricional antropométrico, circunferência de cintura e pressão arterial em adolescentes. Rev Bras Cardiol. 2013;26(2):94-9.

33. Cook DG, Mendall MA, Whincup PH, et al. C-reactive protein concentration in children: relationship to adiposity and other cardiovascular risk factors. Atherosclerosis. 2000;149(1):139-50.

34. Visser M, Bouter LM, McQuillan GM, et al. Low-grade systemic inflammation in overweight children. Pediatrics. 2001;107(1):E13-21.

35. Brasil AR, Norton RC, Rossetti MB, et al. Proteína C reativa como indicador de inflamação de baixa intensidade em crianças e adolescentes com e sem obesidade. J Pediatr (Rio J). 2007;83(5):477-80.

36. Lambert M, Delvin EE, Paradis G, et al. C-reactive protein and features of the metabolic syndrome in a population-based sample of children and adolescents. Clin Chem. 2004;50(10):1762-8.

37. Cardoso-Saldaña G, Juárez-Rojas JG, Zamora-González J, et al. C-reactive protein levels and their relationship with metabolic syndrome and insulin resistance in Mexican adolescents. $J$ Pediatr Endocrinol Metab. 2007;20(7):797-805.

38. Soriano-Guillén L, Hernández-García B, Pita J, et al. High-sensitivity c-reactive protein is a good marker of cardiovascular risk in obese. Eur J Endocrinol. 2008;159(1):R1-4.
39. Ford ES. National Health and Nutrition Examination Survey. C-Reactive Protein Concentration and Cardiovascular Disease Risk Factors in Children: Findings From the National Health and Nutrition Examination Survey 1999-2000. Circulation. 2003;108(9):1053-8.

40. Ford ES, Ajani UA, Mokdad AH. National Health and Nutrition Examination. The metabolic syndrome and concentrations of C-reactive protein among U.S. youth. Diabetes Care. 2005;28(4):878-81.

41. Retnakaran R, Hanley AJ, Connelly PW, et al. Elevated C-reactive protein in Native Canadian children: an ominous early complication of childhood obesity. Diabetes Obes Metab. 2006;8(5):483-91.

42. Wu DM, Chu NF, Shen MH, et al. Obesity, plasma high sensitivity c-reactive protein levels and insulin resistance status among school children in Taiwan. Clin Biochem. 2006;39(8):810-5.

43. Acevedo M, Arnáiz P, Barja S, et al. Relationship of C-Reactive Protein to Adiposity, Cardiovascular Risk Factors, and Subclinical Atherosclerosis in Healthy Children. Rev Esp Cardiol. 2007;60(10):1051-8.

44. Lande MB, Pearson TA, Vermilion RP, et al. Elevated Blood Pressure, Race/Ethnicity, and C-Reactive Protein Levels in Children and Adolescents. Pediatrics. 2008;122(6):1252-7.

45. Oliveira AC, Oliveira AM, Adan LF, et al. C-reactive protein and metabolic syndrome in youth: a strong relationship? Obesity (Silver Spring). 2008;16(5):1094-8.

46. Barja S, Arnaiz P, Domínguez A, et al. Insulinemia e índice HOMA en niños y adolescentes chilenos. Rev Med Chile. 2011;139:1435-43.

47. DeBoer MD, Gurka MJ, Sumner AE. Diagnosis of the metabolic syndrome is associated with disproportionately high levels of high-sensitivity C-reactive protein in non-Hispanic black adolescents: an analysis of NHANES 1999-2008. Diabetes Care. 2011;34(3):734-40. 